\title{
Modified Halpern-type iterative methods for relatively nonexpansive mappings and maximal monotone operators in Banach spaces
}

\author{
Huan-chun $\mathrm{Wu}^{*}$ and Cao-zong Cheng
}

"Correspondence:

wuhuanchun@emails.bjut.edu.cn College of Applied Sciences, Beijing University of Technology, Beijing, 100124, China

\begin{abstract}
We obtain the modified Halpern-type iterative method for finding a common element of the fixed point set of a relatively nonexpansive mapping and the zero set of a maximal monotone operator in a uniformly convex and uniformly smooth Banach space. Our results extend and improve the recent results of Chuang, Lin and Takahashi (J. Glob. Optim. 56:1591-1601, 2013) and Nilsrakoo and Saejung (Appl. Math. Comput. 217:6577-6586, 2011).

MSC: $47 \mathrm{H} 05 ; 47 \mathrm{H} 09 ; 47 \mathrm{~J} 25$
\end{abstract}

Keywords: Halpern-type iterative method; relatively nonexpansive mapping; maximal monotone operator

\section{Introduction}

Let $E$ be a smooth and real Banach space with the dual space $E^{*}$. For $x \in E$ and $x^{*} \in E^{*}$, we denote the value of $x^{*}$ at $x$ by $\left\langle x, x^{*}\right\rangle$. The function $\phi: E \times E \rightarrow \mathbb{R}[1,2]$ is defined by

$$
\phi(x, y)=\|x\|^{2}-2\langle x, J y\rangle+\|y\|^{2} \quad \text { for all } x, y \in E,
$$

where $J$ is the normalized duality mapping from $E$ to $E^{*}$. Let $C$ be a nonempty closed convex subset of $E$. For a mapping $T: C \rightarrow E$, the set of fixed points of $T$ is denoted by Fix $(T)$. A point $a$ in $C$ is called an asymptotic fixed point of $T$ if there exists a sequence $\left\{x_{n}\right\}$ such that $x_{n} \rightarrow a$ and $\lim _{n \rightarrow \infty}\left\|x_{n}-T x_{n}\right\|=0$. The set of asymptotic fixed points is denoted by $\widehat{\operatorname{Fix}}(T)$. A mapping $T: C \rightarrow E$ is relatively nonexpansive (see [3-6]) if the following properties are satisfied:

(i) $\operatorname{Fix}(T) \neq \emptyset$;

(ii) $\phi(p, T x) \leq \phi(p, x)$ for all $p \in \operatorname{Fix}(T), x \in C$;

(iii) $\widehat{\operatorname{Fix}}(T)=\operatorname{Fix}(T)$.

If $T$ satisfies (i) and (ii), then $T$ is called relatively quasi-nonexpansive (see [7]). In a Hilbert space, relatively quasi-nonexpansive mappings coincide with quasi-nonexpansive mappings. Quasi-nonexpansive mappings are investigated by Chuang et al. [8], Yamada and Ogura [9], Kim [10], etc. 
Iterative methods for finding the fixed points of relatively nonexpansive mappings have been studied by many researchers. Matsushita and Takahashi [11] established the Manntype iteration for relatively nonexpansive mappings. Nilsrakoo and Saejung [12] constructed the Halpern-Mann iterative methods for relatively nonexpansive mappings and proved the strong convergence theorem. Matsushita and Takahashi [6] presented the hybrid methods for relatively nonexpansive mappings.

Let $A$ be a maximal monotone operator from $E$ to $2^{E^{*}}$. Several problems in nonlinear analysis and optimization can be formulated to find a point $x \in E$ such that $0 \in A x$. We denote by $A^{-1} 0$ the set of all $x \in E$ with $0 \in A x$. There has been tremendous interest in developing the method for solving zero point problems of maximal monotone operators and related topics (see [13-23]). Zeng et al. [20-22] proposed hybrid proximal-type and hybrid shrinking projection algorithms for maximal monotone operators, relatively nonexpansive mappings and equilibrium problems. Klin-Eam et al. [23] introduced the Halpern iterative method for finding a common element of the zero point set of a maximal monotone operator and the fixed point set of a relatively nonexpansive mapping in a Banach space by using hybrid methods. It is helpful to point out that the methods in [20-23] involve the generalized projections. However, even in Hilbert spaces, sometimes it is hard to compute the generalized projection.

Motivated by Chuang et al. [8] and Nilsrakoo and Saejung [12], we present the modified Halpern-type iterative method for finding a common element of the fixed point set of a relatively nonexpansive mapping and the zero set of a maximal monotone operator. This iterative method is practicable since it does not involve the generalized projections. Our results extend and improve the recent results of some authors.

The paper is organized as follows. Section 2 contains some important concepts and facts. Section 3 is devoted to introducing an iterative scheme and proving a strong convergence theorem. Section 4 provides some examples and numerical results.

\section{Preliminaries}

Throughout this paper, let all Banach spaces be real. Let $E$ be a Banach space with the dual space $E^{*}$. The normalized duality mapping $J: E \rightarrow 2^{E^{*}}$ is defined by

$$
J x=\left\{x^{*} \in E^{*}:\left\langle x, x^{*}\right\rangle=\|x\|^{2}=\left\|x^{*}\right\|^{2}\right\}
$$

for every $x \in E$. By the Hahn-Banach theorem, $J x$ is nonempty for all $x \in E$. In a Hilbert space, the normalized duality mapping $J$ is the identity (see [24] for more details).

A Banach space $E$ is said to be strictly convex if $\left\|\frac{x+y}{2}\right\|<1$ for all $x, y \in E$ with $\|x\|=\|y\|=1$ and $x \neq y$. It is said to be uniformly convex if for every $\epsilon \in(0,2]$, there exists $\delta>0$ such that $\left\|\frac{x+y}{2}\right\|<1-\delta$ for all $x, y \in E$ with $\|x\|=\|y\|=1$ and $\|x-y\| \geq \epsilon$. Let $S_{E}$ be the unit sphere of $E$, that is, $S_{E}:=\{x \in E:\|x\|=1\}$. A Banach space $E$ is said to be smooth if

$$
\lim _{t \rightarrow 0} \frac{\|x+t y\|-\|x\|}{t}
$$

exists for $x, y \in S_{E}$. It is said to be uniformly smooth if the limit (2.2) exists uniformly for $x, y \in S_{E}$. Let us list some well-known facts (see [24, 25]).

(p1) A Banach space $E$ is uniformly smooth if and only if $E^{*}$ is uniformly convex.

(p2) If $E$ is strictly convex, then $J$ is one-to-one. 
(p3) If $E$ is smooth, then $J$ is single-valued.

(p4) If $E$ is reflexive, then $J$ is onto.

(p5) If $E$ is uniformly smooth, then $J$ is uniformly norm-to-norm continuous on each bounded subset of $E$.

Let $E$ be a smooth, strictly convex and reflexive Banach space. The function $\phi: E \times E \rightarrow$ $\mathbb{R}$ defined by (1.1) satisfies

$$
(\|x\|-\|y\|)^{2} \leq \phi(x, y) \leq(\|x\|+\|y\|)^{2}
$$

and

$$
\phi\left(x, J^{-1}(\lambda J y+(1-\lambda) J z)\right) \leq \lambda \phi(x, y)+(1-\lambda) \phi(x, z)
$$

for $\lambda \in[0,1]$ and $x, y, z \in E$.

Let $C$ be a nonempty closed convex subset of a smooth, strictly convex and reflexive Banach space $E$. From Alber [1] and Kamimura and Takahashi [2], the generalized projection $\Pi_{C}$ from $E$ onto $C$ is defined by $\Pi_{C}(x)=\arg \min _{z \in C} \phi(z, x)$ for all $x \in E$. In a Hilbert space $H$, the generalized projection coincides with the nearest metric projection from $H$ onto $C$.

Let $A$ be a set-valued mapping from $E$ to $2^{E^{*}}$ with graph $G(A)=\left\{\left(x, x^{*}\right): x^{*} \in A x\right\}$ and domain $D(A)=\{x \in E: A x \neq \emptyset\}$. It is said to be monotone if $\left\langle x-y, x^{*}-y^{*}\right\rangle \geq 0$ for all $\left(x, x^{*}\right),\left(y, y^{*}\right) \in G(A)$. A monotone operator is maximal if its graph is not properly contained in the graph of any other monotone operator. For a maximal monotone operator $A$ and $r>0$, the resolvent of $A$ is defined by $J_{r} x=(J+r A)^{-1} J x$ for $x \in E$. It is easy to see that $A^{-1} 0=\operatorname{Fix}\left(J_{r}\right)$. The Yosida approximation $A_{r}$ of $A$ is defined by $A_{r} x=\frac{J x-J_{r} x}{r}$ for $x \in E$. Note that $\left(J_{r} x, A_{r} x\right) \in G(A)$.

The following lemmas are useful in the sequel.

Lemma 2.1 [19] Let E be a reflexive, strictly convex and smooth Banach space, and let $V: E \times E^{*} \rightarrow \mathbb{R}$ be defined by

$$
V\left(x, x^{*}\right)=\|x\|^{2}-2\left\langle x, x^{*}\right\rangle+\left\|x^{*}\right\|^{2} .
$$

Then

$$
V\left(x, x^{*}\right)+2\left\langle J^{-1}\left(x^{*}\right)-x, y^{*}\right) \leq V\left(x, x^{*}+y^{*}\right) \quad \text { for all } x \in E \text { and } x^{*}, y^{*} \in E^{*} .
$$

Lemma 2.2 [12] If $E$ is a uniformly smooth Banach space and $r>0$, then there exists a continuous, strictly increasing and convex function $g:[0,2 r] \rightarrow[0, \infty)$ such that $g(0)=0$ and

$$
\phi\left(x, J^{-1}(\lambda J y+(1-\lambda) J z)\right) \leq \lambda \phi(x, y)+(1-\lambda) \phi(x, z)-\lambda(1-\lambda) g(\|J y-J z\|)
$$

for all $\lambda \in[0,1], x \in E$ and $y, z \in B_{r}=\{v \in E:\|v\| \leq r\}$.

Lemma 2.3 [2] Let E be a uniformly convex and smooth Banach space. Suppose that $\left\{x_{n}\right\}$ and $\left\{y_{n}\right\}$ are two sequences of $E$ such that $\left\{x_{n}\right\}$ or $\left\{y_{n}\right\}$ is bounded. If $\phi\left(x_{n}, y_{n}\right) \rightarrow 0$, then $x_{n}-y_{n} \rightarrow 0$. 
Lemma 2.4 [2] Let C be a nonempty closed convex subset of a reflexive, strictly convex and smooth Banach space $E$. If $x \in E$ and $\hat{x} \in E$, then

(1) If $\hat{x}=\Pi_{C} x$ if and only if $\langle y-\hat{x}, J \hat{x}-J x\rangle \geq 0$ for all $y \in C$;

(2) $\phi\left(y, \Pi_{C} x\right)+\phi\left(\Pi_{C} x, x\right) \leq \phi(y, x)$ for all $y \in C$.

Lemma 2.5 [19] Let $E$ be a strictly convex, smooth and reflexive Banach space, and let $A: E \rightarrow 2^{E^{*}}$ be a maximal monotone operator with $A^{-1} 0 \neq \emptyset$. Let $J_{r}=(J+r A)^{-1} J$ for all $r>0$. Then

$$
\phi\left(y, J_{r} x\right)+\phi\left(J_{r} x, x\right) \leq \phi(y, x) \quad \text { for } y \in T^{-1} 0, x \in E .
$$

Lemma 2.6 [26] Let $\left\{a_{n}\right\}$ be a sequence of nonnegative real numbers satisfying $a_{n+1} \leq$ $\left(1-\alpha_{n}\right) a_{n}+\alpha_{n} \beta_{n}$, where

(i) $\left\{\alpha_{n}\right\} \subset(0,1), \sum_{n=1}^{\infty} \alpha_{n}=\infty$;

(ii) $\lim \sup _{n \rightarrow \infty} \beta_{n} \leq 0$.

Then $\lim _{n \rightarrow \infty} a_{n}=0$.

Lemma 2.7 [27] Let $\left\{\Gamma_{n}\right\}$ be a sequence of real numbers that does not decrease at infinity in the sense that there exists a subsequence $\left\{\Gamma_{n_{j}}\right\}$ of $\left\{\Gamma_{n}\right\}$ such that $\Gamma_{n_{j}}<\Gamma_{n_{j}+1}$ for all $j \in \mathbb{N}$. Define the sequence $\{\tau(n)\}_{n \geq n_{0}}$ of integers as follows:

$$
\tau(n)=\max _{k}\left\{k \leq n: \Gamma_{k}<\Gamma_{k+1}\right\},
$$

where $n_{0} \in \mathbb{N}$ such that $\left\{k \leq n_{0}: \Gamma_{k}<\Gamma_{k+1}\right\} \neq \emptyset$. Then the following hold:

(1) $\tau\left(n_{0}\right) \leq \tau\left(n_{0}+1\right) \leq \cdots$ and $\tau(n) \rightarrow \infty$;

(2) $\Gamma_{\tau(n)} \leq \Gamma_{\tau(n)+1}$ and $\Gamma_{n} \leq \Gamma_{\tau(n)+1}$ for all $n \in \mathbb{N}$.

\section{Strong convergence theorems}

In this section, we present the modified Halpern-type iterative method for a relatively nonexpansive mapping and a maximal monotone operator in a uniformly convex and uniformly smooth Banach space.

Theorem 3.1 Let $C$ be a nonempty closed convex subset of a uniformly smooth and uniformly convex Banach space $E$, and let $A: E \rightarrow 2^{E^{*}}$ be a maximal monotone operator with $D(A) \subset C$. Assume that the mapping $T: C \rightarrow E$ is a relatively nonexpansive mapping such that $\operatorname{Fix}(T) \cap A^{-1} 0 \neq \emptyset$. Let $q_{1} \in E$ be arbitrary, and let $\left\{x_{n}\right\}$ be generated by

$$
\left\{\begin{array}{l}
x_{n}=J_{r_{n}} q_{n}, \\
q_{n+1}=J^{-1}\left(\alpha_{n} J u_{n}+\left(1-\alpha_{n}\right)\left(\beta_{n} J x_{n}+\left(1-\beta_{n}\right) J T x_{n}\right)\right),
\end{array}\right.
$$

where $\left\{\alpha_{n}\right\}$ and $\left\{\beta_{n}\right\}$ are sequences in $(0,1)$ and the sequence $\left\{u_{n}\right\}$ is contained in E. Suppose that the following conditions are satisfied:

(c1) $\lim _{n \rightarrow \infty} \alpha_{n}=0$ and $\sum_{n=1}^{\infty} \alpha_{n}=\infty$;

(c2) $\liminf _{n \rightarrow \infty} \beta_{n}\left(1-\beta_{n}\right)>0$;

(c3) $\lim _{n \rightarrow \infty} u_{n}=u$ for some $u \in E$;

(c4) $0<b \leq r_{n}<\infty$.

Then the sequence $\left\{x_{n}\right\}$ converges strongly to $\prod_{\mathrm{Fix}(T) \cap A^{-1} 0} u$. 
Proof It follows from [6, Proposition 2.4] that the set Fix $(T)$ is closed and convex. The set $\operatorname{Fix}(T) \cap A^{-1} 0$ is closed and convex since $A^{-1} 0$ is closed and convex. For simplicity, we write $\Omega:=\operatorname{Fix}(T) \cap A^{-1} 0$.

Set $y_{n}=J^{-1}\left(\beta_{n} J x_{n}+\left(1-\beta_{n}\right) J T x_{n}\right)$. For every $\omega \in \Omega$, we have

$$
\phi\left(\omega, y_{n}\right) \leq \beta_{n} \phi\left(\omega, x_{n}\right)+\left(1-\beta_{n}\right) \phi\left(\omega, T x_{n}\right) \leq \phi\left(\omega, x_{n}\right)
$$

and

$$
\begin{aligned}
\phi\left(\omega, x_{n+1}\right) & =\phi\left(\omega, J_{r_{n+1}} q_{n+1}\right) \\
& \leq \phi\left(\omega, q_{n+1}\right) \\
& =\phi\left(\omega, J^{-1}\left(\alpha_{n} J u_{n}+\left(1-\alpha_{n}\right) J y_{n}\right)\right) \\
& \leq \alpha_{n} \phi\left(\omega, u_{n}\right)+\left(1-\alpha_{n}\right) \phi\left(\omega, y_{n}\right) \\
& \leq \alpha_{n} \phi\left(\omega, u_{n}\right)+\left(1-\alpha_{n}\right) \phi\left(\omega, x_{n}\right) \\
& \leq \max \left\{\phi\left(\omega, u_{n}\right), \phi\left(\omega, x_{n}\right)\right\} .
\end{aligned}
$$

The sequence $\left\{u_{n}\right\}$ is bounded according to condition (c3). It follows that there exists a positive number $M$ such that $\phi\left(\omega, u_{n}\right) \leq M$. Hence, by an easy inductive process, we have

$$
\phi\left(\omega, x_{n+1}\right) \leq \max \left\{\phi\left(\omega, x_{1}\right), M\right\},
$$

which yields that $\left\{x_{n}\right\}$ is bounded. So are $\left\{y_{n}\right\}$ and $\left\{q_{n}\right\}$.

Let $\bar{x}=\Pi_{\operatorname{Fix}(T) \cap A^{-1} 0} u$ and $z_{n}=q_{n+1}=J^{-1}\left(\alpha_{n} J u_{n}+\left(1-\alpha_{n}\right) J y_{n}\right)$. Lemma 2.1 implies that

$$
\begin{aligned}
& \phi\left(\bar{x}, x_{n+1}\right) \\
&= \phi\left(\bar{x}, J_{r_{n+1}} q_{n+1}\right) \\
& \leq \phi\left(\bar{x}, J^{-1}\left(\alpha_{n} J u_{n}+\left(1-\alpha_{n}\right) J y_{n}\right)\right) \\
&= V\left(\bar{x}, \alpha_{n} J u_{n}+\left(1-\alpha_{n}\right) J y_{n}\right) \\
& \leq V\left(\bar{x}, \alpha_{n} J u_{n}+\left(1-\alpha_{n}\right) J y_{n}-\alpha_{n}\left(J u_{n}-J \bar{x}\right)\right) \\
&-2\left\langle J^{-1}\left(\alpha_{n} J u_{n}+\left(1-\alpha_{n}\right) J y_{n}\right)-\bar{x},-\alpha_{n}\left(J u_{n}-J \bar{x}\right)\right\rangle \\
&= V\left(\bar{x}, \alpha_{n} J \bar{x}+\left(1-\alpha_{n}\right) J y_{n}\right)+2 \alpha_{n}\left\langle z_{n}-\bar{x}, J u_{n}-J \bar{x}\right\rangle \\
&= \phi\left(\bar{x}, J^{-1}\left(\alpha_{n} J \bar{x}+\left(1-\alpha_{n}\right) J y_{n}\right)\right)+2 \alpha_{n}\left\langle z_{n}-\bar{x}, J u_{n}-J \bar{x}\right\rangle \\
& \leq\left(1-\alpha_{n}\right) \phi\left(\bar{x}, x_{n}\right)+2 \alpha_{n}\left\langle z_{n}-\bar{x}, J u_{n}-J u+J u-J \bar{x}\right\rangle \\
&=\left(1-\alpha_{n}\right) \phi\left(\bar{x}, x_{n}\right)+2 \alpha_{n}\left(\left\langle z_{n}-\bar{x}, J u_{n}-J u\right\rangle+\left\langle z_{n}-\bar{x}, J u-J \bar{x}\right\rangle\right) .
\end{aligned}
$$

We divide the rest of the proof into two cases.

Case 1. Suppose that there exists $n_{0} \in \mathbb{N}$ such that $\phi\left(\bar{x}, x_{n+1}\right) \leq \phi\left(\bar{x}, x_{n}\right)$ for all $n \geq n_{0}$.

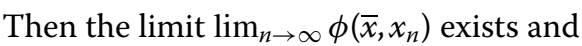

$$
\lim _{n \rightarrow \infty}\left(\phi\left(\bar{x}, x_{n+1}\right)-\phi\left(\bar{x}, x_{n}\right)\right)=0
$$


It follows from Lemma 2.2 that there exists a continuous, strictly increasing and convex function $g:[0,2 r] \rightarrow[0, \infty)$ such that $g(0)=0$ and

$$
\phi\left(\bar{x}, y_{n}\right) \leq \phi\left(\bar{x}, x_{n}\right)-\beta_{n}\left(1-\beta_{n}\right) g\left(\left\|J T x_{n}-J x_{n}\right\|\right),
$$

where $r=\sup _{n}\left\{\left\|x_{n}\right\|,\left\|T x_{n}\right\|\right\}$. Hence, we have

$$
\begin{aligned}
& \phi\left(\bar{x}, x_{n+1}\right) \\
& \quad \leq \alpha_{n} \phi\left(\bar{x}, u_{n}\right)+\left(1-\alpha_{n}\right) \phi\left(\bar{x}, y_{n}\right) \\
& \quad \leq \alpha_{n} \phi\left(\bar{x}, u_{n}\right)+\left(1-\alpha_{n}\right)\left[\phi\left(\bar{x}, x_{n}\right)-\beta_{n}\left(1-\beta_{n}\right) g\left(\left\|J T x_{n}-J x_{n}\right\|\right)\right] \\
& \quad \leq \phi\left(\bar{x}, x_{n}\right)+\alpha_{n} L-\left(1-\alpha_{n}\right) \beta_{n}\left(1-\beta_{n}\right) g\left(\left\|J T x_{n}-J x_{n}\right\|\right),
\end{aligned}
$$

where $L=\sup _{n}\left\{\phi\left(\bar{x}, u_{n}\right)-\phi\left(\bar{x}, x_{n}\right)\right\}$. This yields that

$$
\left(1-\alpha_{n}\right) \beta_{n}\left(1-\beta_{n}\right) g\left(\left\|J T x_{n}-J x_{n}\right\|\right) \leq \phi\left(\bar{x}, x_{n}\right)-\phi\left(\bar{x}, x_{n+1}\right)+\alpha_{n} L .
$$

Therefore, we conclude that

$$
\lim _{n \rightarrow \infty}\left\|J T x_{n}-J x_{n}\right\|=0 .
$$

This together with property $(\mathrm{p} 5)$ gives that

$$
\lim _{n \rightarrow \infty}\left\|T x_{n}-x_{n}\right\|=0
$$

Observe that

$$
\phi\left(T x_{n}, y_{n}\right) \leq \beta_{n} \phi\left(T x_{n}, x_{n}\right)+\left(1-\beta_{n}\right) \phi\left(T x_{n}, T x_{n}\right) \rightarrow 0
$$

and

$$
\phi\left(y_{n}, z_{n}\right) \leq \alpha_{n} \phi\left(y_{n}, u_{n}\right)+\left(1-\alpha_{n}\right) \phi\left(y_{n}, y_{n}\right) \rightarrow 0 .
$$

Lemma 2.3 implies that $T x_{n}-y_{n} \rightarrow 0$ and $y_{n}-z_{n} \rightarrow 0$. Thus, we get

$$
\lim _{n \rightarrow \infty}\left\|x_{n}-z_{n}\right\|=0
$$

Next, we prove that

$$
\limsup _{n \rightarrow \infty}\left\langle z_{n}-\bar{x}, J u-J \bar{x}\right\rangle \leq 0
$$

Thanks to (3.6), we have

$$
\limsup _{n \rightarrow \infty}\left\langle z_{n}-\bar{x}, J u-J \bar{x}\right\rangle=\limsup _{n \rightarrow \infty}\left\langle x_{n}-\bar{x}, J u-J \bar{x}\right\rangle .
$$


We choose a subsequence $\left\{x_{n_{j}}\right\}$ of $\left\{x_{n}\right\}$ such that

$$
\limsup _{n \rightarrow \infty}\left\langle z_{n}-\bar{x}, J u-J \bar{x}\right\rangle=\lim _{j \rightarrow \infty}\left\langle x_{n_{j}}-\bar{x}, J u-J \bar{x}\right\rangle .
$$

In view of the boundedness of $\left\{x_{n_{j}}\right\}$, without loss of generality, we assume that $x_{n_{j}} \rightarrow p$. Now we show that $p \in \Omega$. According to the definition of $T$ and (3.5), one has $p \in \operatorname{Fix}(T)$. It is sufficient to show that $p \in A^{-1} 0$. For all $\left(h, h^{*}\right) \in G(A)$, one has

$$
\left\langle h-J_{r_{n_{j}}} q_{n_{j}}, h^{*}-A_{r_{n_{j}}} q_{n_{j}}\right\rangle \geq 0 .
$$

Lemma 2.5 implies that

$$
\begin{aligned}
\phi\left(x_{n+1}, q_{n+1}\right) & \leq \phi\left(\bar{x}, q_{n+1}\right)-\phi\left(\bar{x}, x_{n+1}\right) \\
& \leq \alpha_{n} \phi\left(\bar{x}, u_{n}\right)+\left(1-\alpha_{n}\right) \phi\left(\bar{x}, x_{n}\right)-\phi\left(\bar{x}, x_{n+1}\right) \\
& \leq \alpha_{n}\left[\phi\left(\bar{x}, u_{n}\right)-\phi\left(\bar{x}, x_{n}\right)\right]+\phi\left(\bar{x}, x_{n}\right)-\phi\left(\bar{x}, x_{n+1}\right),
\end{aligned}
$$

which yields that $x_{n+1}-q_{n+1} \rightarrow 0$, i.e.,

$$
\lim _{n \rightarrow \infty}\left\|x_{n}-q_{n}\right\|=0
$$

Consequently, we get

$$
A_{r_{n_{j}}} q_{n_{j}}=\frac{\left\|J q_{n_{j}}-J x_{n_{j}}\right\|}{r_{n_{j}}} \rightarrow 0 .
$$

Recall that $x_{n_{j}}=J_{r_{j}} q_{n_{j}} \rightarrow p$. Thus, the maximality of $A$ implies $p \in A^{-1} 0$. Indeed, we have $p \in \Omega$. By (3.8) and Lemma 2.4, we have

$$
\begin{aligned}
\limsup _{n \rightarrow \infty}\left\langle z_{n}-\bar{x}, J u-J \bar{x}\right\rangle & =\lim _{j \rightarrow \infty}\left\langle x_{n_{j}}-\bar{x}, J u-J \bar{x}\right\rangle \\
& =\langle p-\bar{x}, J u-J \bar{x}\rangle \\
& \leq 0 .
\end{aligned}
$$

Thus, inequality (3.7) holds.

Using (3.2), (3.7) and Lemma 2.6, we see that the sequence $\left\{x_{n}\right\}$ converges strongly to $\bar{x}$. Case 2. Suppose that there exists a subsequence $\left\{n_{j}\right\}$ of $\{n\}$ such that

$$
\phi\left(\bar{x}, x_{n_{j}}\right)<\phi\left(\bar{x}, x_{n_{j}+1}\right)
$$

for all $j \in \mathbb{N}$. By Lemma 2.7, there is a nondecreasing sequence such that $\tau(n) \rightarrow \infty$,

$$
\phi\left(\bar{x}, x_{\tau(n)}\right) \leq \phi\left(\bar{x}, x_{\tau(n)+1}\right) \quad \text { and } \quad \phi\left(\bar{x}, x_{n}\right) \leq \phi\left(\bar{x}, x_{\tau(n)+1}\right)
$$

for all $n \in \mathbb{N}$. Expression (3.4) implies that

$$
\begin{gathered}
\left(1-\alpha_{\tau(n)}\right) \beta_{\tau(n)}\left(1-\beta_{\tau(n)}\right) g\left(\left\|J T x_{\tau(n)}-J x_{\tau(n)}\right\|\right) \\
\leq \phi\left(\bar{x}, x_{\tau(n)}\right)-\phi\left(\bar{x}, x_{\tau(n)+1}\right)+\alpha_{\tau(n)} M .
\end{gathered}
$$


Hence, we have

$$
\lim _{n \rightarrow \infty}\left\|T x_{\tau(n)}-x_{\tau(n)}\right\|=0 .
$$

It follows from (3.6) that

$$
\lim _{n \rightarrow \infty}\left\|x_{\tau(n)}-q_{\tau(n)+1}\right\|=0 .
$$

By (3.9), one has

$$
\lim _{n \rightarrow \infty}\left\|x_{\tau(n)+1}-q_{\tau(n)+1}\right\|=0 .
$$

Combining (3.13) and (3.14) gives

$$
\lim _{n \rightarrow \infty}\left\|x_{\tau(n)+1}-x_{\tau(n)}\right\|=0 .
$$

It follows from (3.13) and (3.15) that

$$
\begin{aligned}
& \limsup _{n \rightarrow \infty}\left\langle z_{\tau(n)}-\bar{x}, J u-J \bar{x}\right\rangle \\
& \quad=\lim _{j \rightarrow \infty}\left\langle x_{\tau\left(n_{j}\right)}-\bar{x}, J u-J \bar{x}\right\rangle \\
& \quad=\lim _{j \rightarrow \infty}\left\langle x_{\tau\left(n_{j}\right)+1}-\bar{x}, J u-J \bar{x}\right\rangle .
\end{aligned}
$$

An argument similar to the one in Case 1 shows that

$$
\limsup _{n \rightarrow \infty}\left\langle z_{\tau(n)}-\bar{x}, J u-J \bar{x}\right\rangle \leq 0 .
$$

By (3.2), we have

$$
\begin{aligned}
& \phi\left(\bar{x}, x_{\tau(n)+1}\right) \\
& \quad \leq\left(1-\alpha_{\tau(n)}\right) \phi\left(\bar{x}, x_{\tau(n)}\right)+2 \alpha_{\tau(n)}\left(\left\langle z_{\tau(n)}-\bar{x}, J u_{\tau(n)}-J u\right\rangle+\left\langle z_{\tau(n)}-\bar{x}, J u-J \bar{x}\right\rangle\right),
\end{aligned}
$$

which yields that

$$
\phi\left(\bar{x}, x_{\tau(n)}\right) \leq 2\left(\left\langle z_{\tau(n)}-\bar{x}, J u_{\tau(n)}-J u\right\rangle+\left\langle z_{\tau(n)}-\bar{x}, J u-J \bar{x}\right\rangle\right) .
$$

This together with (3.17) implies that $\phi\left(\bar{x}, x_{\tau(n)}\right) \rightarrow 0$. It follows from (3.18) that $\phi\left(\bar{x}, x_{\tau(n)+1}\right) \rightarrow 0$. Then we have $x_{n} \rightarrow \bar{x}$ according to the fact that $\phi\left(\bar{x}, x_{n}\right) \leq \phi\left(\bar{x}, x_{\tau(n)+1}\right)$. The proof is completed.

Remark 1 Letting $u=0$ in our result, we obtain the algorithm for minimal-norm solutions of the corresponding problem.

Remark 2 When $A=\partial \delta_{C}$ (that is, the subdifferential of the indicator function of $C$ ) and $q_{1}=x_{1}$, Theorem 3.1 improves and extends the result of Nilsrakoo and Saejung [12, Theorem 3.4] in which the variable $u_{n}$ is reduced to the constant $u$. 
Now, we apply our result to the equilibrium problem. Let $C$ be a nonempty closed convex subset of a uniformly smooth and uniformly convex Banach space $E$, and let $f$ be a bifunction from $C \times C$ to $\mathbb{R}$. The equilibrium problem is to find $\bar{x} \in C$ such that

$$
f(\bar{x}, y) \geq 0 \quad \text { for all } y \in C .
$$

The set of solutions of (3.19) is denoted by $E P(f)$. Numerous problems in physics, optimization and economics can be reduced to finding a solution of the equilibrium problem (for instance, see [28]). The equilibrium problem has been studied extensively (see [7, 8, 28-33]).

For solving the equilibrium problem, we assume that the bifunction $f$ satisfies the following conditions:

(a1) $f(x, x)=0$ for all $x \in C$;

(a2) $f$ is monotone, i.e., $f(x, y)+f(y, x) \leq 0$ for all $x, y \in C$;

(a3) For every $x, y, z \in C, \lim \sup _{t \downarrow 0} f(t z+(1-t) x, y) \leq f(x, y)$;

(a4) $f(x, \cdot)$ is convex and lower semicontinuous for all $x \in C$.

Takahashi and Zembayashi [33] obtained the following result.

Proposition 3.2 [33] Let $C$ be a nonempty closed convex subset of a uniformly smooth and strictly convex Banach space $E$, and let $f$ be a bifunction from $C \times C$ to $\mathbb{R}$ satisfying (a1)-(a4). For $r>0$, define a mapping $T_{r}: E \rightarrow 2^{C}$ as follows:

$$
T_{r}(x)=\left\{z \in C: f(z, y)+\frac{1}{r}\langle y-z, J z-J x\rangle \geq 0 \text { for all } y \in C\right\}
$$

for all $x \in E$. Then the following hold:

(r1) $T_{r}$ is single-valued;

(r2) $T_{r}$ is a firmly nonexpansive-type mapping, i.e., for $x, y \in E$, $\left\langle T_{r} x-T_{r} y, J x-J y\right\rangle \geq\left\langle T_{r} x-T_{r} y, J T_{r} x-J T_{r} y\right\rangle ;$

(r3) $\operatorname{Fix}\left(T_{r}\right)=E P(f)$;

(r4) $E P(f)$ is closed and convex.

We call $T_{r}$ the resolvent of $f$ for $r>0$. The following result is a specialized case of the result of Aoyama et al. [30, Theorem 3.5].

Proposition 3.3 Let $C$ be a nonempty closed convex subset of a uniformly smooth and uniformly convex Banach space $E$, and let $f$ be a bifunction from $C \times C$ to $\mathbb{R}$ satisfying (a1)-(a4). Let $A_{f}$ be a set-valued mapping of E into $2^{E^{*}}$ defined by

$$
A_{f} x= \begin{cases}\left\{x^{*} \in E^{*}: f(x, y) \geq\left\langle y-x, x^{*}\right\rangle \text { for all } y \in C\right\} & \text { if } x \in C, \\ \varnothing & \text { if } x \notin C .\end{cases}
$$

Then $A_{f}$ is a maximal monotone operator with $D\left(A_{f}\right) \subset C$ and $E P(f)=A_{f}^{-1} 0$. Furthermore, for $r>0$, the resolvent $T_{r}$ off coincides with the resolvent $\left(J+r A_{f}\right)^{-1} J$ of $A_{f}$.

Using Theorem 3.1 and Proposition 3.3, we get the following result. 
Corollary 3.4 Let $C$ be a nonempty closed convex subset of a uniformly smooth and uniformly convex Banach space $E$, and let $f$ be a bifunction from $C \times C$ to $\mathbb{R}$ satisfying (a1)(a4). Assume that the mapping $T: C \rightarrow E$ is a relatively nonexpansive mapping such that $\operatorname{Fix}(T) \cap E P(f) \neq \emptyset$. Let $q_{1} \in E$ and $\left\{x_{n}\right\}$ be generated by

$$
\left\{\begin{array}{l}
x_{n} \in C \text { such that } f\left(x_{n}, y\right)+\frac{1}{r_{n}}\left\langle y-x_{n}, J x_{n}-J q_{n}\right\rangle \geq 0 \quad \text { for all } y \in C, \\
q_{n+1}=J^{-1}\left(\alpha_{n} J u_{n}+\left(1-\alpha_{n}\right)\left(\beta_{n} J x_{n}+\left(1-\beta_{n}\right) J T x_{n}\right)\right),
\end{array}\right.
$$

where $\left\{\alpha_{n}\right\}$ and $\left\{\beta_{n}\right\}$ are sequences in $(0,1)$ and the sequence $\left\{u_{n}\right\}$ is contained in $E$. If conditions (c1)-(c4) are satisfied, then the sequence $\left\{x_{n}\right\}$ converges strongly to $\Pi_{\operatorname{Fix}(T) \cap E P(f)} u$.

Remark 3 Corollary 3.4 improves and extends Theorem 3.4 of Chuang et al. [8].

\section{Numerical experiments}

In this section, we give some examples and numerical results to illustrate our result in the preceding section.

Example 4.1 Let $E=\mathbb{R}$ and $C_{1}=[-4,4]$. The mapping $T_{1}: C_{1} \rightarrow E$ is defined by

$$
T_{1} x= \begin{cases}0 & \text { if } x=0, \\ \frac{x}{2} \cos \frac{1}{x} & \text { if } x \in C_{1} \backslash\{0\} .\end{cases}
$$

We claim that $T_{1}$ is a relatively nonexpansive mapping. In fact, it follows from $\operatorname{Fix}\left(T_{1}\right)=$ $\{0\}$ that

$$
\left|T_{1} x-0\right| \leq\left|\frac{x}{2} \cos \frac{1}{x}-0\right| \leq|x-0| \text { for all } x \in[-4,4] .
$$

However, $T_{1}$ is not nonexpansive. To show this, it is sufficient to take $x=\frac{2}{3 \pi}$ and $y=\frac{1}{\pi}$ (for more details, see [34]). Let $A_{1}$ be the subdifferential of the indicator function of $C_{1}$. It follows from [35, Theorem A] that $A_{1}$ is a maximal monotone operator. The resolvent $J_{r}^{(1)}$ is the metric projection onto $C_{1}$, namely, for all $r>0$,

$$
J_{r}^{(1)} x= \begin{cases}4 & \text { if } x \geq 4 \\ x & \text { if }-4<x<4 \\ -4 & \text { if } x \leq-4\end{cases}
$$

Let $\alpha_{n}=\frac{1}{n+1}, \beta_{n}=\frac{2}{3}-\frac{1}{n+1}, u_{n}=\frac{3 n-1}{4 n}$, and $r_{n}=\frac{1}{3}$. Then all the assumptions and conditions in Theorem 3.1 are satisfied. Given $q_{1}=-0.8$, the numerical result is shown in Figure 1 .

Example 4.2 Let $E=\mathbb{R}$ and $C_{2}=[-0.5,0.5]$. The mapping $T_{2}: C_{2} \rightarrow E$ is defined by

$$
T_{2} x=x^{2} \quad \text { for } x \in[-0.5,0.5]
$$

It is a relatively nonexpansive mapping. Moreover, the mapping $T_{2}$ is nonexpansive. For all $x, y \in[-0.5,0.5]$, we see that

$$
\left|T_{2} x-T_{2} y\right| \leq\left|x^{2}-y^{2}\right| \leq|x+y| \cdot|x-y| \leq|x-y| .
$$


Figure 1 Numerical result for Example 4.1.

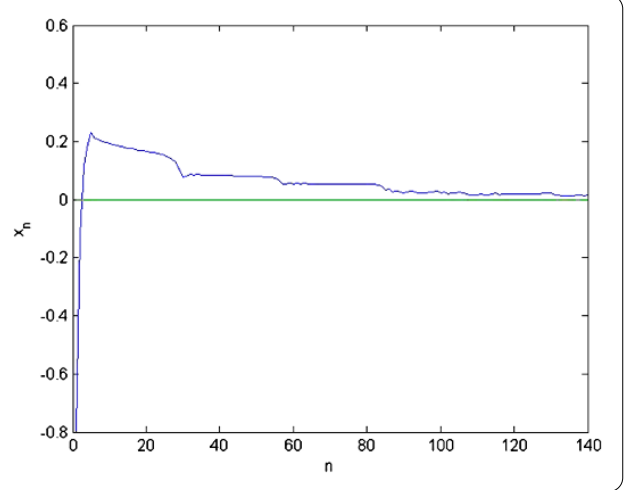

Figure 2 Numerical result for Example 4.2.

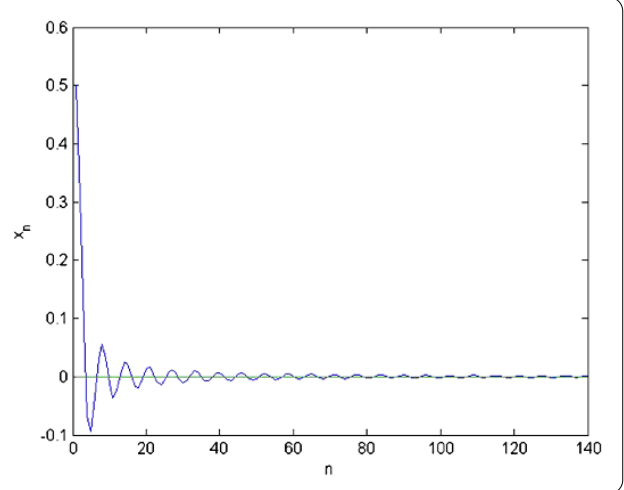

Let $A_{2}$ be the subdifferential of the indicator function of $C_{2}$. By an argument similar to the one in Example 4.1, the resolvent $J_{r}^{(2)}$ is defined as follows.

$$
J_{r}^{(2)} x= \begin{cases}0.5 & \text { if } x \geq 0.5 \\ x & \text { if }-0.5<x<0.5 \\ -0.5 & \text { if } x \leq-0.5\end{cases}
$$

Let $\alpha_{n}=\frac{1}{\ln (n+2)}, \beta_{n}=\frac{1}{2}-\frac{1}{n+3}, u_{n}=\frac{\sin n}{n+1}$, and $r_{n}=\frac{1}{6}$. Putting $q_{1}=1.5$, the numerical result is given in Figure 2 .

Remark 4 Figures 1 and 2 show that when an iteration step $n$ is greater than 100 and 60 in Examples 4.1 and 4.2 respectively, the term $x_{n}$ is close to the desired element. Therefore, our iterative method is effective.

Competing interests

The authors declare that they have no competing interests.

\section{Authors' contributions}

All authors read and approved the final manuscript.

\section{Acknowledgements}

The authors would like to thank reviewers and editors for their valuable comments and suggestions. This work was supported by graduate funds of Beijing University of Technology (no. ykj-2013-9422). 


\section{References}

1. Alber, YI: Metric and generalized projection operators in Banach spaces: properties and applications. In: Kartsatos, AG (ed.) Theory and Applications of Nonlinear Operators of Accretive and Monotone Type. Lecture Notes in Pure and Applied Mathematics, vol. 178, pp. 15-50. Dekker, New York (1996)

2. Kamimura, S, Takahashi, W: Strong convergence of a proximal-type algorithm in a Banach space. SIAM J. Optim. 13, 938-945 (2003)

3. Butnariu, D, Reich, S, Zaslavski, AJ: Asymptotic behavior of relatively nonexpansive operators in Banach spaces. J. Appl. Anal. 7, 151-174 (2001)

4. Butnariu, D, Reich, S, Zaslavski, AJ: Weak convergence of orbits of nonlinear operators in reflexive Banach spaces. Numer. Funct. Anal. Optim. 24, 489-508 (2003)

5. Censor, Y, Reich, S: Iterations of paracontractions and firmly nonexpansive operators with applications to feasibility and optimization. Optimization 37, 323-339 (1996)

6. Matsushita, SY, Takahashi, W: A strong convergence theorem for relatively nonexpansive mappings in a Banach space. J. Approx. Theory 134, 257-266 (2005)

7. Qin, XL, Cho, YJ, Kang, SM: Convergence theorems of common elements for equilibrium problems and fixed point problems in Banach spaces. J. Comput. Appl. Math. 225, 20-30 (2009)

8. Chuang, CS, Lin, LJ, Takahashi, W: Halpern's type iterations with perturbations in Hilbert spaces: equilibrium solutions and fixed points. J. Glob. Optim. 56, 1591-1601 (2013)

9. Yamada, I, Ogura, N: Hybrid steepest descent method for variational inequality problem over the fixed point set of certain quasi-nonexpansive mappings. Numer. Funct. Anal. Optim. 25, 619-655 (2004)

10. Kim, GE: Weak and strong convergence theorems of quasi-nonexpansive mappings in a Hilbert space. J. Optim. Theory Appl. 152, 727-738 (2012)

11. Matsushita, SY, Takahashi, W: Weak and strong convergence theorems for relatively nonexpansive mappings in Banach spaces. Fixed Point Theory Appl. 2004(1), 37-47 (2004)

12. Nilsrakoo, W, Saejung, S: Strong convergence theorems by Halpern-Mann iterations for relatively nonexpansive mappings in Banach spaces. Appl. Math. Comput. 217, 6577-6586 (2011)

13. Rockafellar, RT: Monotone operators and proximal point algorithm. SIAM J. Control Optim. 14, $877-898$ (1976)

14. Kamimura, S, Takahashi, W: Approximating solutions of maximal monotone operators in Hilbert spaces. J. Approx. Theory 106, 226-240 (2000)

15. Xu, HK: A regularization method for the proximal point algorithm. J. Glob. Optim. 36, 115-125 (2006)

16. Ceng, LC, Khan, AR, Ansari, QH, Yao, JC: Strong convergence of composite iterative schemes for zeros of $m$-accretive operators in Banach spaces. Nonlinear Anal. 70, 1830-1840 (2009)

17. Ceng, LC, Ansari, QH, Schaible, S, Yao, JC: Hybrid viscosity approximation method for zeros of $m$-accretive operators in Banach spaces. Numer. Funct. Anal. Optim. 33, 142-165 (2012)

18. Saejung, S: A supplement to a regularization method for the proximal point algorithm. J. Glob. Optim. 56, 121-129 (2013)

19. Kohsaka, F, Takahashi, W: Strong convergence of an iterative sequence for maximal monotone operators in a Banach space. Abstr. Appl. Anal. 2004(3), 239-249 (2004)

20. Zeng, LC, Ansari, QH, Shyu, DS, Yao, JC: Strong and weak convergence theorems for common solutions of generalized equilibrium problems and zeros of maximal monotone operators. Fixed Point Theory Appl. 2010, Article ID 590278 (2010)

21. Ceng, LC, Ansari, QH, Yao, JC: Hybrid proximal-type and hybrid shrinking projection algorithms for equilibrium problems, maximal monotone operators, and relatively nonexpansive mappings. Numer. Funct. Anal. Optim. 31, 763-797 (2010)

22. Zeng, LC, Ansari, QH, Al-Homidan, S: Hybrid proximal-type algorithms for generalized equilibrium problems, maximal monotone operators, and relatively nonexpansive mappings. Fixed Point Theory Appl. 2011, Article ID 973028 (2011)

23. Klin-Eam, C, Suantai, S, Takahashi, W: Generalized projection algorithms for maximal monotone operators and relatively nonexpansive mappings in Banach spaces. Taiwan. J. Math. 15, 1227-1246 (2011)

24. Cioranescu, I: Geometry of Banach Spaces, Duality Mappings and Nonlinear Problems. Kluwer Academic, Dordrecht (1990)

25. Agarwal, RP, O'Regan, D, Sahu, DR: Fixed Point Theory for Lipschitzian-Type Mappings with Applications. Springer, Berlin (2009)

26. $\mathrm{Xu}, \mathrm{HK}$ : Another control condition in an iterative method for nonexpansive mappings. Bull. Aust. Math. Soc. 65 109-113 (2002)

27. Mainge, PE: Strong convergence of projected subgradient methods for nonsmooth and nonstrictly convex minimization. Set-Valued Anal. 16, 899-912 (2008)

28. Blum, E, Oettli, W: From optimization and variational inequalities to equilibrium problems. Math. Stud. 63, 123-145 (1994)

29. Combettes, PL, Hirstoaga, SA: Equilibrium programming in Hilbert spaces. J. Nonlinear Convex Anal. 6, 117-136 (2005)

30. Aoyama, K, Kimura, Y, Takahashi, W: Maximal monotone operators and maximal monotone functions for equilibrium problems. J. Convex Anal. 15, 395-409 (2008)

31. $\mathrm{Wu}, \mathrm{HC}$, Cheng, $\mathrm{CZ}$ : Iterative methods for equilibrium problems and monotone inclusion problems in Hilbert spaces. J. Appl. Math. 2013, Article ID 280909 (2013)

32. Wu, HC, Cheng, CZ: Approximations for equilibrium problems and nonexpansive semigroups. Abstr. Appl. Anal. 2014 Article ID 351372 (2014)

33. Takahashi, W, Zembayashi, K: Strong and weak convergence theorems for equilibrium problems and relatively nonexpansive mappings in Banach spaces. Nonlinear Anal. 70, 45-57 (2009)

34. Kim, GE: Weak and strong convergence for quasi-nonexpansive mappings in Banach spaces. Bull. Korean Math. Soc 49, 799-813 (2012)

35. Rockafellar, RT: On the maximal monotonicity of subdifferential mappings. Pac. J. Math. 33, $209-216$ (1970) 
10.1186/1687-1812-2014-237

Cite this article as: Wu and Cheng: Modified Halpern-type iterative methods for relatively nonexpansive mappings and maximal monotone operators in Banach spaces. Fixed Point Theory and Applications 2014, 2014:237

Submit your manuscript to a SpringerOpen ${ }^{\circ}$ journal and benefit from:

- Convenient online submission

- Rigorous peer review

- Immediate publication on acceptance

Open access: articles freely available online

- High visibility within the field

- Retaining the copyright to your article

Submit your next manuscript at $\gg$ springeropen.com 